\title{
Territórios de atenção à saúde: dinâmicas urbanísticas e sociais
}

\section{Territories of health care: urban and social dynamics}

\author{
Nádile Juliane Costa de Castro 11
}

\begin{abstract}
Resumo: Identifica as dinâmicas da territorialização a partir de um equipamento de saúde. A pesquisa ocorreu na Unidade Saúde da Família situada em um município da Amazônia paraense, participante do Programa de Melhoria do Acesso e da Qualidade na Atenção Básica (PMAQ). Estudo de caso pela proposta qualitativa e de observação participante. Identificou-se que há déficit de infraestrutura urbanística e social no entrono do equipamento de saúde. Há atendimento da população descoberta, entretanto de forma insuficiente em função do déficit de inserção no plano municipal de saúde da área em destaque, resultando em possibilidades de subnotificações de morbidades e problemas socioambientais que podem implicar na saúde do indivíduo.
\end{abstract}

Palavras-chave: Saúde coletiva, direito sanitário, saúde, territórios.

\begin{abstract}
It identifies the dynamics of territorialization from a health equipment. The research was carried out at the Family Health Unit located in a municipality in the Amazon region of Para, a participant in the Program for Improving Access and Quality in Primary Care (PMAQ). Case study by the qualitative proposal and participant observation. It was identified that there is a deficit of urban and social infrastructure in the health equipment environment. There is insufficient attention to the population of the population due to the deficiency of insertion in the municipal health plan of the highlighted area, resulting in the possibility of underreporting of morbidities and socioenvironmental problems that may imply the health of the individual.
\end{abstract}

Keywords: Collective health, health law, Cheers, territories.

\section{Introdução}

$\mathrm{Na}$ atualidade abrangendo questões relativas aos territórios de saúde e suas dinâmicas, de modo mais expansivo e como promoção da qualidade de vida, as políticas e ações são construídas por uma visão de agregação das organizações, não sendo focada somente em um único campo, como por exemplo, a saúde. De fato, tem envolvido outros setores como a educação, emprego e lazer (GOMES, BASTOS, FERES, 2016). É uma política integrada, interdisciplinar e direcionada pelas novas políticas públicas consolidadas, o que para a área da saúde implica em direitos sanitários previstos desde a Constituição Federal de 1988.

\footnotetext{
${ }^{1}$ Doutoranda em ciências socioambientais (NAEA/UFPA). Mestre em doenças tropicais (NMT/UFPA). Bolsista CAPES. E-mail: nadiledecastro@hotmail.com
} 
No Brasil a descentralização política-administrativa, baseada na Constituição Federal promoveu mudanças no sentido de distribuir as competências nas três esferas de poder, substituindo a centralização do poder, que implicou em políticas sociais ampliadas quanto os direitos de cidadania, que deveras ocorreu por meio de definições de diretrizes para promover gestão política e social (BREVILHERI, NARCISO, PASTOR, 2014). Estas novas configurações e divisões também ocorreram por meio da saúde pela Lei Orgânica da Saúde de 1990, através da delimitação territorial em saúde. Esta reorganização reflete diretamente no planejamento das ações em saúde, pois, entre tantos objetivos, advém também a caracterização do território por meio de mapas geográficos para adequação do equipamento de saúde à realidade (FARIA, BORTOZOLI, 2009; SANTOS, 2017).

Partindo destas assertivas e para a compreensão da importância da organização do espaço urbano, se entende que no contexto de infraestrutura este deve possuir equipamentos para execução da educação em saúde, além de serviços que incluem rede de esgotos, transporte, coleta de lixo e iluminação pública. Ademais, considerando como base o pensamento de Maricato (2011), quando da existência de investimento e condições viáveis de moradia, e para implementação destes, alguns fatos paralelos devem ser identificados. O que se busca nessa direção é perceber a ocorrência de concentração populacional, que por vezes, caracteriza estes locais como apropriados ou não.

Todos estes aspectos são importantes ao se estabelecer mudanças na organização e demais ensejos a serem inclusos nesses espaços e como previsto na Política Nacional de Promoção à Saúde (PNPS), pois implica em estabelecer relações com as demais políticas (MALTA et al., 2016). Outrora, no sentido urbanístico, a população mais privilegiada por estas situações de falências de organização do espaço urbano é a parcela da população com maior poder aquisitivo, pois realiza a acumulação de espaços urbanos e/ou apropriação, e acaba por interferir indiretamente no modo de vida daqueles espaços. Esta situação condiciona padrões e muitas vezes exclui parcelas da população em virtude de um "ilhamento" de condições de vida com condições mais satisfatórias quanto de infraestrutura.

Considerando estes aspectos Souza (2008) descreve que para evitar ou diminuir 
estas problemáticas é necessário planejar e gerir, pois o mesmo prepara para o futuro e para os imprevistos, respectivamente. É, portanto, a participação da sociedade nesse processo que visa garantir alguns direitos, seja qual área de ocorrência. No caso deste estudo, é pontuado a constituição da democracia pela participação em eventos intersetoriais, sendo estes condicionantes para a rede de saúde, pois, implica em desenvolver a democracia de diversos setores, inclusive a democracia sanitária, que gera condições favoráveis para a garantia da qualidade de vida pelas estratégias de saúde como apontado em estudos da área (AITH, 2015).

É pertinente também priorizar a política de inclusão social, pois, pelas suas proposições exige uma integração do espaço urbano por meio de saneamento básico, inclusão de endereço e segurança. Há, porém, de se considerar que a mesma por si só não melhora os níveis de escolaridade (e de conhecimento) que seria um dos aportes para mudanças de posturas de seus participantes. Em verdade, ainda que presente, mas de participantes com déficits de conhecimento e ensino, poderá não permitir agregar todas as partes inclusas no processo de organização do espaço, pela ausência de participação ativa em função do desconhecimento da causa ou de uma participação efetiva (MARICATO, 2011). Contudo, existem instrumentos sociais como o plano diretor municipal, que é democrático e permite a participação de várias camadas da sociedade, ainda que haja esses entraves e possibilidades de cenários.

Para reverter processos de exclusão social, cita-se o plano diretor, que é um instrumento de gestão, de cunho democrático, apresenta um significativo potencial para reverter dinâmicas excludentes pela participação social. Este permite por meio da área das políticas públicas a discussão de demandas de saúde ambiental e populações vulneráveis. Deste modo, há uma condução concreta tanto a propriedade urbana, como a rede urbana, cumprindo sua função social, afirmando o direito de reivindicar não pelo direito da moradia saudável em si, mas pelo direito à cidade, com todos a atributos que ela possa oferecer (PEREIRA, 2009).

Ainda, dentro da perspectiva de exclusão, mas nos interesses da saúde, é importante buscar articulações que norteiam a noção de valor à vida e a saúde. É um modo operante em que não se faz ações de saúde pontuais direcionadas ao sofrimento 
agudo. Entretanto, permite resgatar o valor da vida e da saúde assim como da cidadania e dignidade do cidadão (CARNEIRO JR, SILVEIRA 2003).

Por certo, dentro dos princípios do SUS, a implementação de políticas e programas que contemplem os vários aspectos envolvidos no processo saúde-doença, com o propósito de alcançar o seu objeto ajudaria a contemplar estes aspectos (CARNEIRO JR, SILVEIRA, 2003). Por certo, considerando estes fatos, é perceptível identificar que a territorialização em saúde sempre deve ser considerada nesse processo, haja vista que incorpora os aspectos da dinâmica do território. Os desdobramentos desse processo envolvem a articulação sociais, ambientais e gestores no serviço de saúde demonstrando os delineamentos da territorialização.

Nesta direção, o trabalho tem por objetivo identificar as dinâmicas da territorialização a partir de um equipamento de saúde. A pesquisa ocorreu na Unidade Saúde da Família situada em um município da Amazônia paraense, participante do Programa de Melhoria do Acesso e da Qualidade na Atenção Básica (PMAQ).

\section{Metodologia}

Estudo de abordagem qualitativa, e por meio de estudo de caso único (YIN, 2016). A pesquisa foi divindade em dois momentos: Primeiro: Levantamento teórico acerca da organização dos serviços de saúde de acordo com o tema central que abrange território e planejamento, baseado principalmente nos pensamentos de política urbana de Villaça (1999) e Maricato (2011), e posteriormente foi desenvolvida uma reflexão teórica da inclusão urbanística como estratégia de organização do espaço e suporte para diminuição das iniquidades. Segundo momento: Construção da pesquisa com procedimento de métodos mistos.

A coleta de dados foi realizada por meio da observação não participante, onde o autor realizou visita técnica ao local da pesquisa. A técnica fotográfica foi utilizada como registro dos espaços, que de acordo com Simonian (2006) auxilia na identificação dos conhecimentos científicos, incluindo a materialização, pois, identifica, analisa e entende o imaginário, assim como as sensações.

A partir desta configuração, houve associação de coletas de dados, sendo a pri- 
meira de campo de caráter qualitativa e descritiva (CRESWELL,2013) e a segunda por meio de registros fotográficos. O equipamento de saúde está localizado no bairro de Águas Lindas, no município de Castanhal-PA, pertencente a região metropolitana II, com nome fantasia no Cadastro Nacional de Estabelecimento de Saúde (CNES) como Unidade Saúde da Família Dr. Luis Charlet. Este é caracterizado como unidade básica, com serviços de baixa complexidade, que possui administração direta da saúde, com composição de duas equipes do Estratégia Saúde da Família e sendo participante do Programa de Melhoria do Acesso e da Qualidade na Atenção Básica (PMAQ).

Como critério de inclusão foram registrados espaços de abrangência do serviço de saúde conforme mapa disponível na unidade de saúde. E para análise do material utilizamos a técnica de Bardin (2011) que trabalha com a análise de conteúdo que é um conjunto de técnicas de análise de comunicações visando obter, por procedimentos sistemáticos e objetivos de descrição de conteúdo das mensagens, indicadores (quantitativos ou não) que permitam a inferência de conhecimentos relativos às condições de produção/recepção destas.

\section{RESULTADOS E DISCUSSÃO}

\subsection{O município de Castanhal}

Em comparação as outras regiões brasileiras, a região Norte se apresenta com processo histórico diferenciado, pois tem uma ocupação espacial, o clima, o baixo índice socioeconômico, conflitos agrários, problemas ambientais, aspectos culturais fortes, e todas as características físicas, incluindo seus distanciamentos geográficos e territoriais especialmente incomuns. Estes permeiam um acesso territorial dentro do estado e entre outros estados, com dificuldades para quem necessita utilizá-lo. Todas estas características não têm sido usadas como referências para as políticas setoriais, que de fato se baseiam em modelos referenciados pela região centro-sul, com características diferentes da região amazônica (HOLANDA, NEGRÃO, 2013).

É necessário, portanto, compreender o cenário e suas características próprias, a fim de usá-las nos planejamentos, o que possibilita resultados que alcancem as necessidades locais e/ou regionais, pois são fatores importantes quando do planejamento 
em saúde. Ademais, as ocupações de territórios da Amazônia legal passaram por processos que mudaram as dinâmicas de suas populações e ocorrem até a atualidade em função dos contínuos investimentos na região em função do modelo capitalista. Deste modo, compreender e identificar a dinâmica do município de Castanhal é pertinente, pois oferece o cenário real para implicações de políticas públicas democráticas.

Nesta lógica, o município de Castanhal, que foi fundado em 1963, e está a 65 quilômetros de Belém (Pará) em referência ao seu centro, estando entre as cinco principais cidades do Estado, possui uma área 1.029,191 km² e população 159.110 hab. est. IBGE/2008 com densidade 147,8 hab. $/ \mathrm{km}^{2}$. Está localizada a margem da rodovia federal BR-316 - a principal via de ligação entre a capital paraense e as regiões Nordeste, Centro-Oeste, Sudeste e Sul, item indispensável para o escoamento da produção, em conexão com aeroporto e da Alça Viária, na região metropolitana de Belém. Possui um polo industrial em implantação na PA-10, distante $5 \mathrm{~km}$ do centro municipa $\left.\right|^{2}$

Apresenta atualmente uma rede urbana que possui fluxos direcionados a várias cidades da região, servindo de suporte, por meio da BR-316, para áreas de turismo e cidades de outras regiões do estado do Pará. Essa posição hierárquica conforme Costa (2015) que o município de Castanhal ocupa na rede urbana sub-regional do nordeste paraense aponta a mesma como cidade que possui fluxos econômicos que se apresenta dentro da perspectiva citada por Holanda e Negrão (2009), que diz que cidades se tornam segregadas, em função de uma política urbana desconexa. Isto tem como resultado espaços periféricos que possuem moradias inadequadas, onde o acesso a serviços e equipamentos urbanos é deficiente.

A cidade de Castanhal apresenta características comuns as cidades da Amazônia. Em virtude de aspectos como demografia, distanciamento da capital e toda a organização de seus espaços onde incluem os equipamentos, serviços e sua função econômica na sub-região. É portanto, uma cidade média, pelas singularidades apresentadas quanto os múltiplos serviços oferecidos e suas relações na rede urbana que estão atreladas ao nordeste paraense (COSTA, 2015).

Entretanto, é percebido que a cidade de Castanhal possui diversos problemas

\footnotetext{
${ }^{2}$ As informações da presente seção foi retirada do site: www.castanhal.gov.br (Acesso em : 10 de Maio de 2015) e do Instituto Brasileiro de Geografia e Estatística - IBGE (2010).
} 
urbanos como a ocupação ilegal do solo, nas localidades de "Jagatá", "Nova Estrela, "Campos Lindos", "Nova Olinda II”. Há áreas precárias de urbanização com falta de infraestrutura urbana (iluminação deficiente, ausência de cobertura por equipamento de saúde, coleta de lixo irregular) e distantes das realidades das áreas mais estruturadas como o centro da cidade. O centro é de fato, onde há a concentração da rede comercial, que estão emancipadas pelo capital, entretanto apresentam problemas sociais como moradores de rua.

Essas características se baseiam na inserção do modelo econômico capitalista, que segundo Costa (2000), são características do desenvolvimento econômico da contemporaneidade. Estas incluem aumento do contingente populacional de moradores de rua e outras denominações de exclusão social. São dinâmicas conforme Da Trindade Jr (2006) resultantes da modernização que vai além da urbanização da população e do território, e que deve ser compreendido como processo de fluidez do território.

São condições deveras preocupante, pois incluem populações em situação de vulnerabilidade. Neste caso, a ausência de moradia, implica em situações de vulnerabilidade ao indivíduo em vários aspectos sendo um deles os serviços de saúde, pois, dificulta a acessibilidade aos diversos programas, mas também, essa condição implica em determinantes sociais em saúde, como o trabalho (FERRAZ, BATISTA, 2017). Estes fatos demostram como o contexto social, político e econômico podem interferir na saúde, reafirmando estes fatores como condicionantes contrários a promoção da saúde (SOUSA et al., 2017).

Outra característica observada no território de Castanhal é a expansão de populações advindas de outros municípios. Isto ocorre em virtude da polarização de serviços de educação superior públicos e privados, que vem crescendo continuamente nos últimos anos. São situações que possibilitaram a dinamização espacial, financeira e aumento da especulação imobiliária, principalmente ao redor destes serviços, mas não somente neles, pois direciona mudanças nos serviços de saúde e segurança principalmente.

\subsection{Estrutura e organização do território de Saúde}

A unidade de saúde possui duas equipes saúde da família consideradas completas (inclui todos os profissionais de acordo com a estrutura do ESF - médico, enfermeiro, 
odontólogo, técnico de enfermagem, agente comunitário de saúde e auxiliar de consultório dentário), Núcleo de apoio a saúde da família (NASF) e dois programas de referência a saúde da criança, os testes de triagem neonatal - para teste do pezinho e teste da Orelhinha, que atendem além da população de Castanhal, a população de outros municípios circunvizinhos. No ato da pesquisa o teste de triagem neonatal (teste do pezinho) estava suspenso por falta de profissional de nível técnico treinado para realização das atividades no equipamento de saúde estudado.

Este dado evidencia a importância do município na região do nordeste paraense e assim como da mesma forma, a importância da Unidade Saúde da Família (USF) Luís Charlet como um equipamento de referência para determinados serviços. Considerase então sua demanda diferenciada apesar de estar enquadrado como um serviço de demanda territorial específica.

Possui uma estrutura física ampla (Figura 1, 2 e 3), de alvenaria, forrada, com cerâmica no revestimento, com ar-condicionado em todas as áreas, incluindo sala de espera coletiva. Constituída de consultórios, farmácia, sala de vacina (sendo está não construída no padrão previsto pelo ministério da saúde, pois apresenta a mesma porta para entrada e saída dos usuários) consultório dentário, arquivo, salas de exames específicas, salas de apoio e serviços. Todo o espaço físico da unidade contempla os serviços previstos na organização da USF.

Não há dados concretos quanto à quantidade de famílias cadastradas no serviço. Alguns livros de registro apontam que a equipe 01 atende aproximadamente 1100 usuários e a equipe 2, 900 usuários, além dos atendimentos as áreas descobertas. Estas últimas não possuem registro quantitativo, não podendo ser mesuradas para estimativa da área descoberta, haja vista que não há divisão do público da área descoberta e da demanda de serviços de referência.

Os atendimentos realizados, em sua totalidade ultrapassam o quantitativo de atendimento previsto pelo Ministério da Saúde. Este é delimitado por área, e assim definido seu quantitativo, porém, há também os atendimentos por fluxo espontâneo, em virtude das triagens neonatais e NASF, tecendo outros valores além dos limites. Há neste fato e na falta de organização dos registros, a elucidação de que a configuração do equipa- 
mento de saúde deve ser revista pela gestão em saúde do município de Castanhal, no sentido de permitir um atendimento de qualidade e dentro dos parâmetros previstos.

Ainda neste contexto, essas situações demostram que o próprio serviço não possui uma organização espacial, baseada no território e condicionada à legislação de saúde. Somente há mapas que definem as micro áreas delimitadas (Figura 4), entretanto, não configuram de modo real a população atendida. Deste modo, poderá haver implicação na qualidade da assistência, que tem necessidade de ser reestruturada por meio de planos diretores a saúde, ou pela reorganização do planejamento urbano da cidade. Entende-se que esta organização foi criada no intuito de perceber dentro da organização do modelo de território em saúde, que a apresentação espacial possui interferência direta na saúde do indivíduo, haja vista que orienta as escolhas e defini os fatores de risco a saúde da população. Pinto e Jorge (2015, p. 1527) citam este contexto quanto os serviços e sociedade e esclarecem que fatos como estes são determinantes sociais e de saúde, e estão presentes por diversas redes que envolvem o serviço, e incluso a infraestrutura em geral.

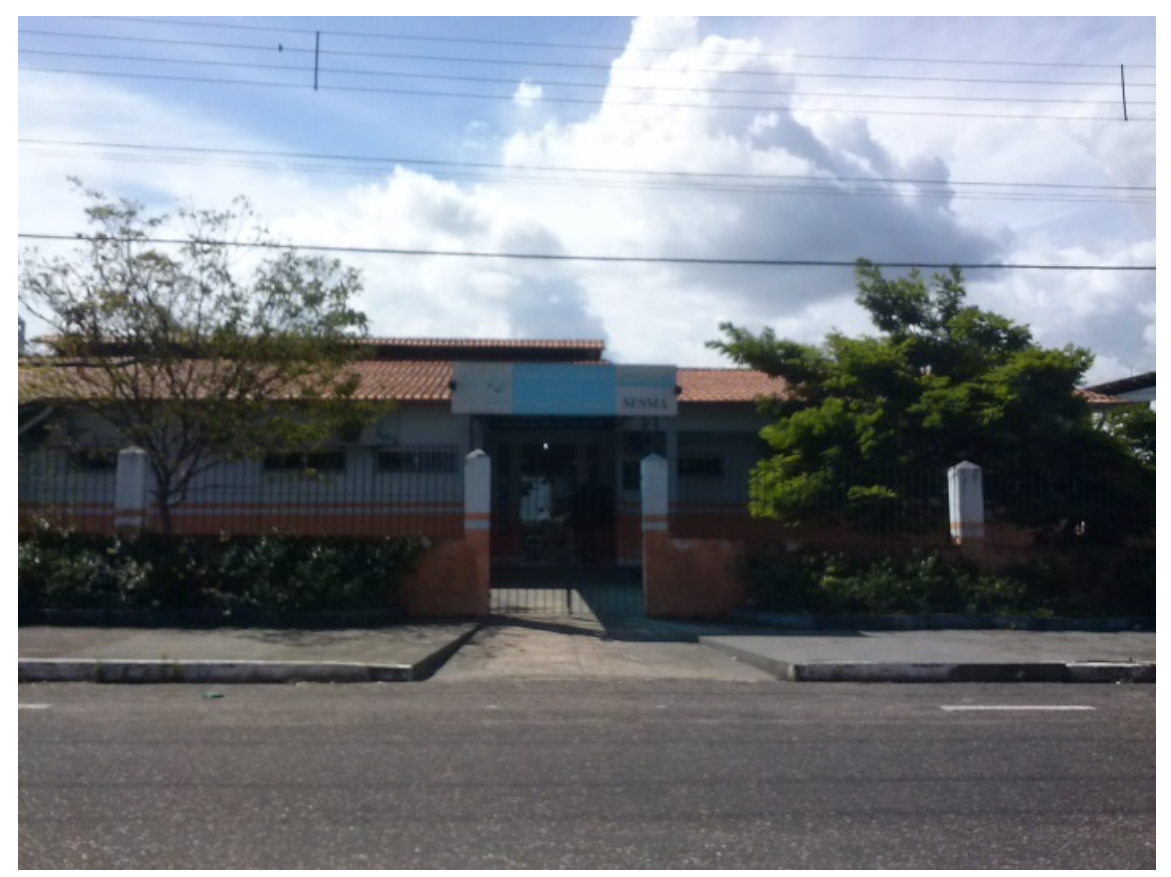

Figura 1. Equipamento de saúde. Fonte: arquivo pessoal

Apesar dos usuários estarem sendo atendidos nestes serviços, é pertinente dizer que esta demanda é oriunda da própria busca do usuário pelo serviço no caso da área 


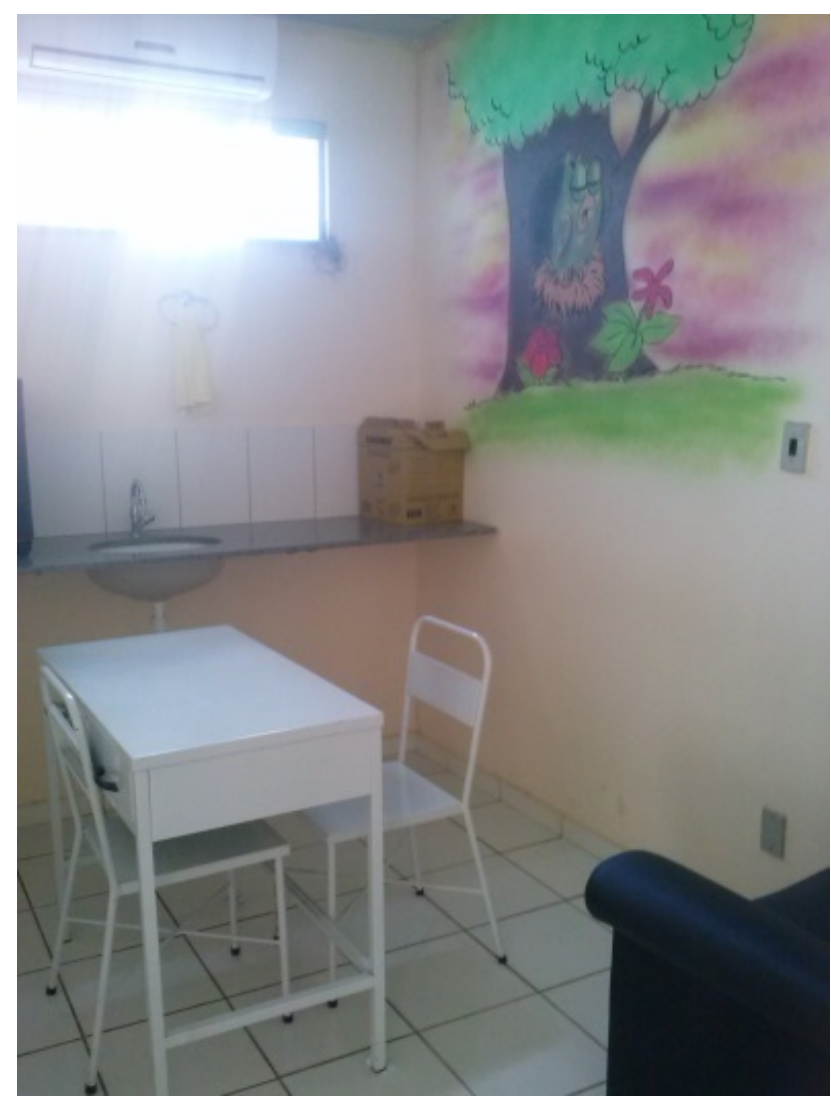

Figura 2. Espaço do serviço de triagem. Fonte: arquivo pessoal

descoberta. Nos outros casos, estes dados aplicam-se a busca ativa por meio das visitas domiciliares e rotinas dos programas. Contudo, há situações recorrentes da área descoberta ocorre em função dos mesmos não estarem incluídos nas rotinas da visita domiciliaria da equipe.

Dos Santos e Kirschbaum (2008), identifica a visita domiciliária como instrumento que adentra as casas da população, promovendo saúde e estreitando relações, o que implica em consequências à saúde coletiva. Já para Paim e Almeida-Filho (1998) é um movimento ideológico de caráter social, que por meio desta transformação revela dimensão social, ambiental, respeitando a história, e sendo capaz de respeitar o processo saúde-doença-cuidado de forma integral. Ainda conforme Jack, Dicenso e Lohfeld (2016) a visita domiciliar cria vínculos, afetos e ajuda na prestação dos serviços de saúde. Além de promover efetivamente maior conhecimento para os usuários do serviço pelas implicações interpessoais mais estreitas (GLATT et al., 2016)

Destaca-se como a visita domiciliaria sendo um instrumento do equipamento de 


\section{Revista Ciências da Sociedade (RCS), Vol. 2, n. 4, p.162-180, Ju/Dez 2018}

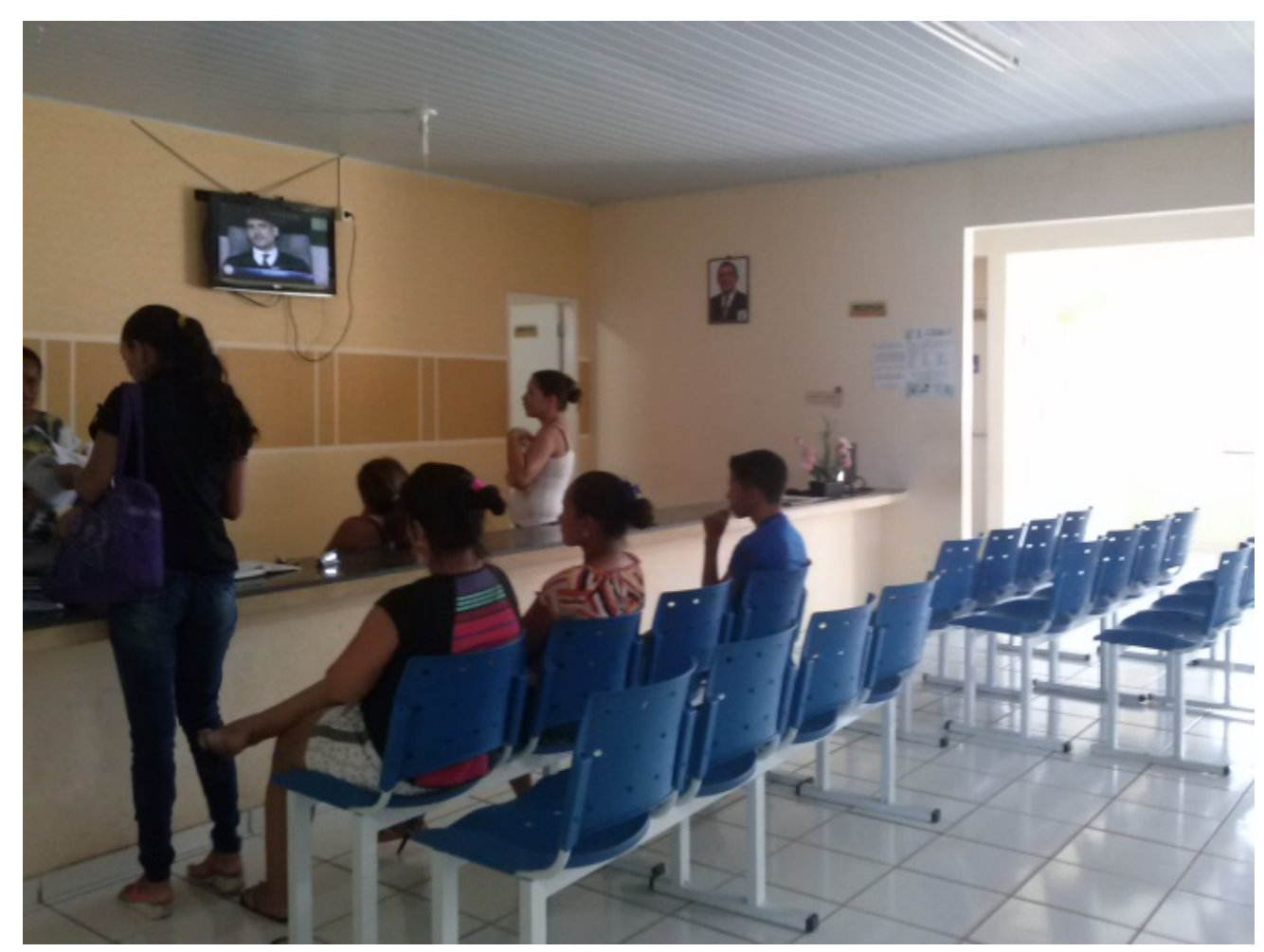

Figura 3. Sala de espera. Fonte: arquivo pessoal

saúde, implica de forma indireta na democratização pelos serviços da população atendida, tornando a atividade de inclusão social. Há, no entanto, a necessidade de estimular os representantes políticos e a própria sociedade para a participação nos debates urbanos sociais, em detrimento de identificar e comunicar os órgãos competentes sobre estas condições. A visita, portanto, é um dos instrumentos que deve ser amplamente discutido nessas ações, pois caracteriza os aspectos da territorialização construída.

Para compreensão destas afirmativas é válido entender que são os habitantes que conhecem suas realidades e conseguem identificar o que é necessário para seu território (OLIVEIRA, LIMA, 2016). Neste sentido, a participação social se torna de grande importância, porque por meio dela há uma intensa discussão das necessidades da comunidade e deste modo seus atores percebem como esta ferramenta pode ser utilizada a fim de fiscalizar os serviços, os trabalhadores de saúde e seus direitos. Todos estes apontamentos indicam um pensamento de coletividade e "empoderamento comunitário" (SIPRIANO, MOREIRA, MORATO, 2015).

Fazendo um paralelo com a participação social na perspectiva das políticas públicas urbanísticas, pelo pensamento de Maricato (2011), os avanços urbanos, e suas 
Revista Ciências da Sociedade (RCS), Vol. 2, n. 4, p.162-180, Ju//Dez 2018

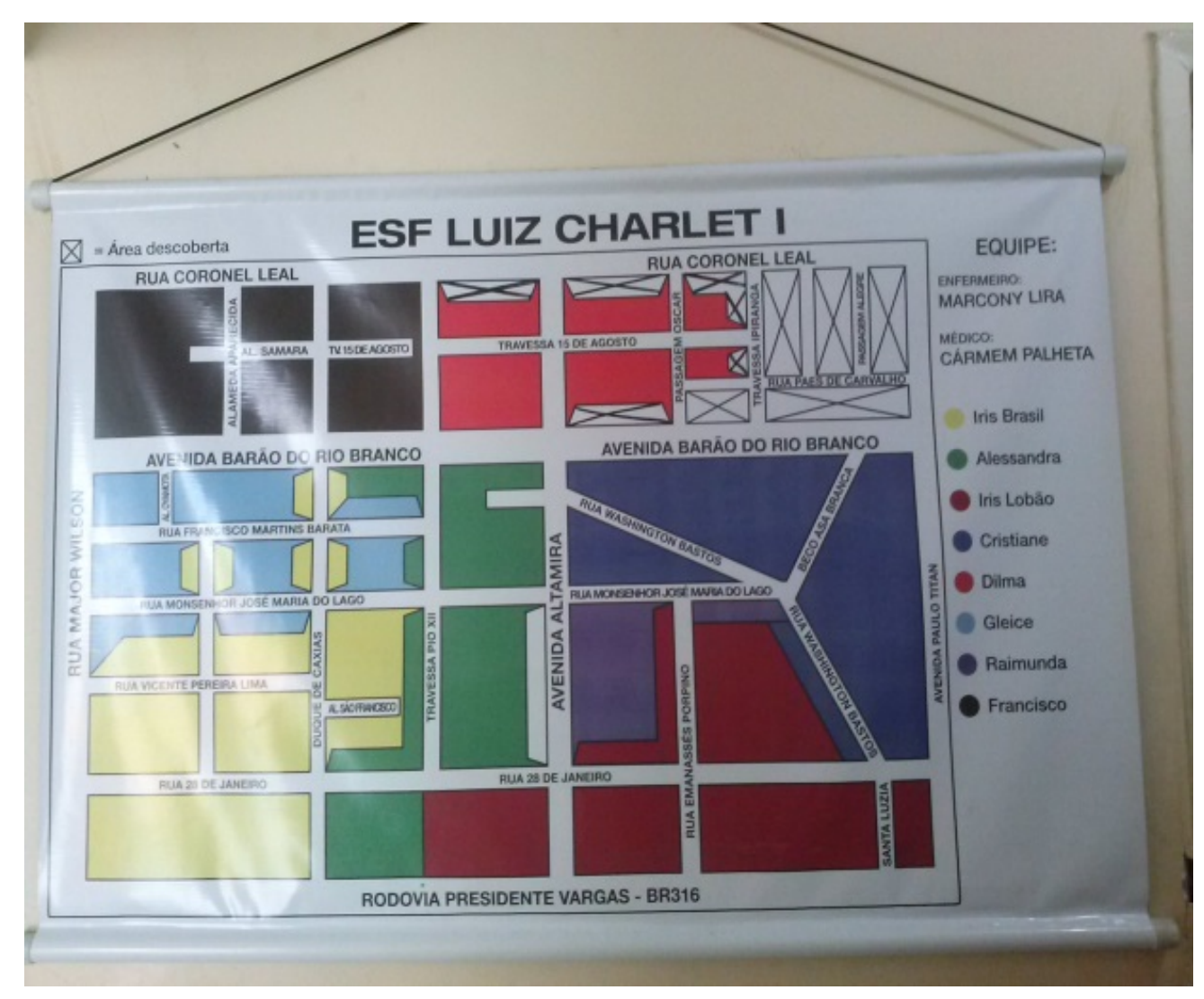

Figura 4. Mapa de delimitação das micro áreas. Fonte: arquivo pessoal

conquistas estão condicionados as forças sociais, entretanto estão subordinadas as condições políticas. E para serem implementadas dependem destes, mas não em sua totalidade, o que para isso é viável anunciar uma sociedade em renovação. Por certo, estes avanços estão ligados aos direitos fundamentais do cidadão que envolvem moradia e participação popular, assim como do direito a cidade, o que devem ser discutidas a fim que ocorra uma implementação satisfatória (DIAS, FIGUEIREDO, 2015).

\section{Organização espacial da área descoberta}

A área descoberta apresenta caraterísticas peculiares de um setor com déficits de assistência urbana, incluso: deficiências como saneamento básico (Figura 5 e 6), ausência de adequação de calçadas, meio fio e residências sem padronização (Figura 7). Situação semelhante encontrada por Machado et al (2015) onde os serviços de saneamento básico não atingem toda a população de seu estudo, assim como no estudo de Dos Santos et al (2015).

A partir de Oliveira et al (2015) é possível entender como cenários como estes 
precisam de equilíbrio. Para o alcance desta condição há de se envolver questões econômicas, sociais e ecológicas a partir da conscientização do próprio indivíduo. Ademais, ao perceber o cenário e sua inserção estadual, é relevante considerar a fala de Souza (2015, p. 261) quanto a gestão de saneamento básico no estado do Pará:

"A definição de controle social apresentada repete a que foi proposta pela Lei Federal n. ${ }^{\circ} 11.445 / 2007$, muito teórica e pouco prática, deixando abertas as mesmas lacunas nela existentes. Além disso, o legislador paraense, por um lado, cria uma instância colegiada deliberativa e inserta no Sistema Estadual de Saneamento como órgão máximo e, por outro lado, se reporta à possibilidade de o controle social ser exercido por meio de uma instância colegiada consultiva."

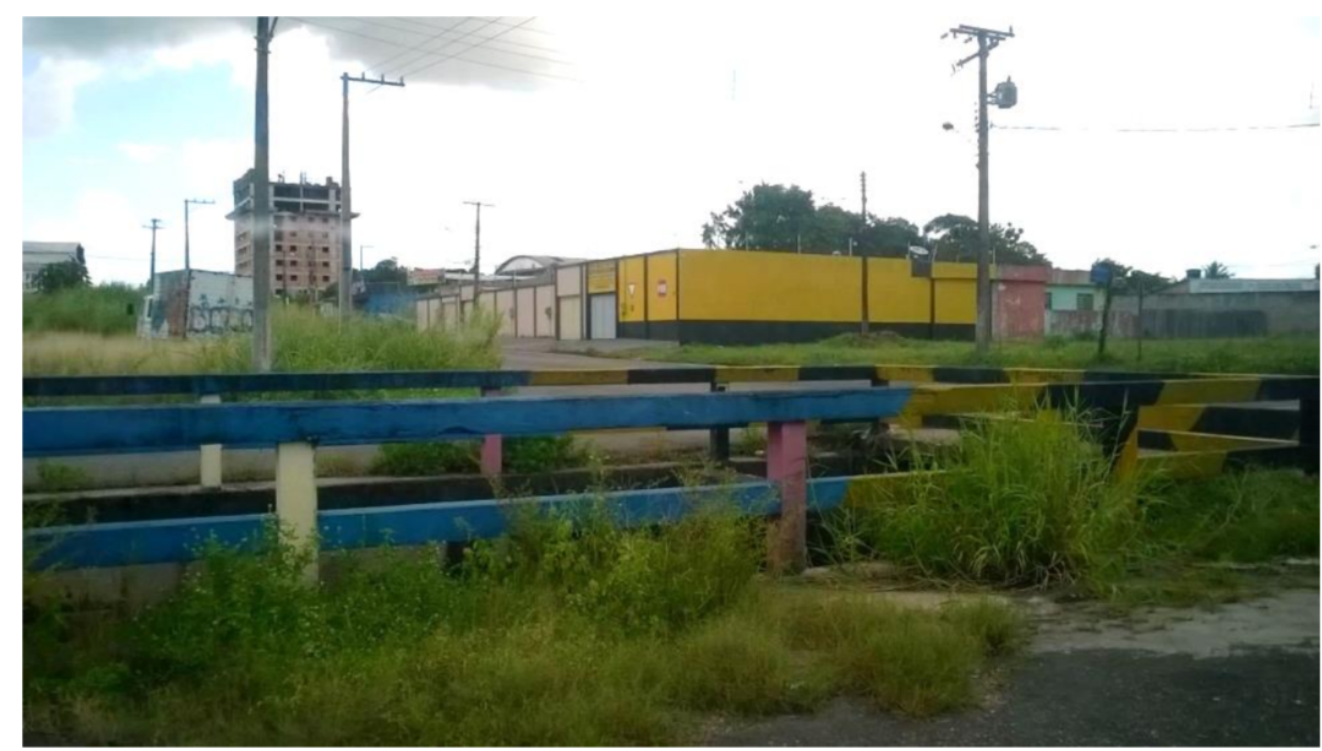

Figura 5. Canal aberto Fonte: Arquivo pessoal

Esta área em ocupação desordenada no município de Castanhal não tem cobertura em totalidade pela atenção básica em saúde, não possuindo de forma integral o direito a determinados serviços da equipe saúde da família. Esta condição inclui as atividades do agente comunitário de saúde, que é um importante agente no processo de identificação de situações de riscos inerentes à saúde. Neste caso, se espera a ocorrência de problemas como a não identificação de agravos inerentes a condições ambientais e sociais, e que podem se apresentar em conjunto com as precariedades do espaço urbano em problemáticas de saúde, caracterizadas por problemas de ordem higiênico sanitário, multiplicando casos de patologias que são resultados da falta de organização do espaço e do planejamento social. 


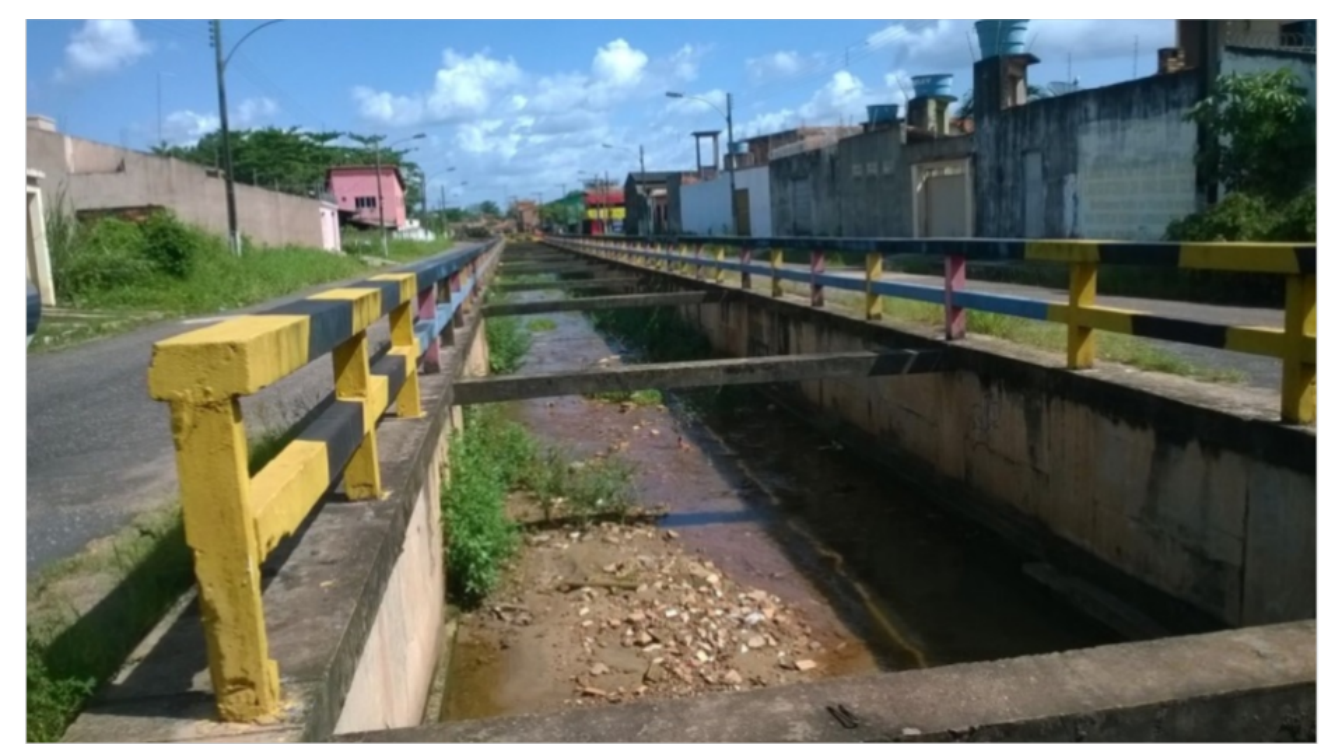

Figura 6. Canal aberto 2 Fonte: Arquivo pessoal

Estas necessidades poderiam ser debatidas e referenciadas por meio da participação democrática prevista no Estatuto das Cidades, o que pode ser realizado no município em questão. Baseado nisto, se observa a necessidade de discutir a estrutura desses espaços em construção, no sentido de revelar seus problemas. Logo, a população de Castanhal deve ter participação por meio de seus representantes, no sentido de articular melhorias nos serviços e espaços usados por esses equipamentos. Por certo, ainda encontramos situações reveladas por Santos (2015) o que nos leva a questionar como de fato estas políticas irão funcionar na prática.

Nesta direção, a gestão democrática das cidades deve ser baseada em debates, audiências, consultas públicas e conferências, que configuram a ação orçamentária participativa, onde a política urbana utiliza como instrumento ${ }^{2}$. No caso de Castanhal, segundo Mercês (2011), não há definições relativas ao congresso da cidade, não havendo definições dos critérios de gêneros dos componentes dos conselhos da cidade.

Como ponto de partida de acordo com Villaça (1999), o planejamento urbano seria um processo continuo onde se revelaria problemas urbanos, cujas soluções seriam objeto de integração de aspectos econômicos, físicos, sociais e políticos. Entretanto, estes planos, que se iniciam com enormes volumes, elaborados por equipes multidisciplinares e que citam vários problemas, resultam em projetos de lei, com poucas informações, apenas publicado no Diário Oficial. É de fato, um desafio, mas há como ocorrer, inclu- 


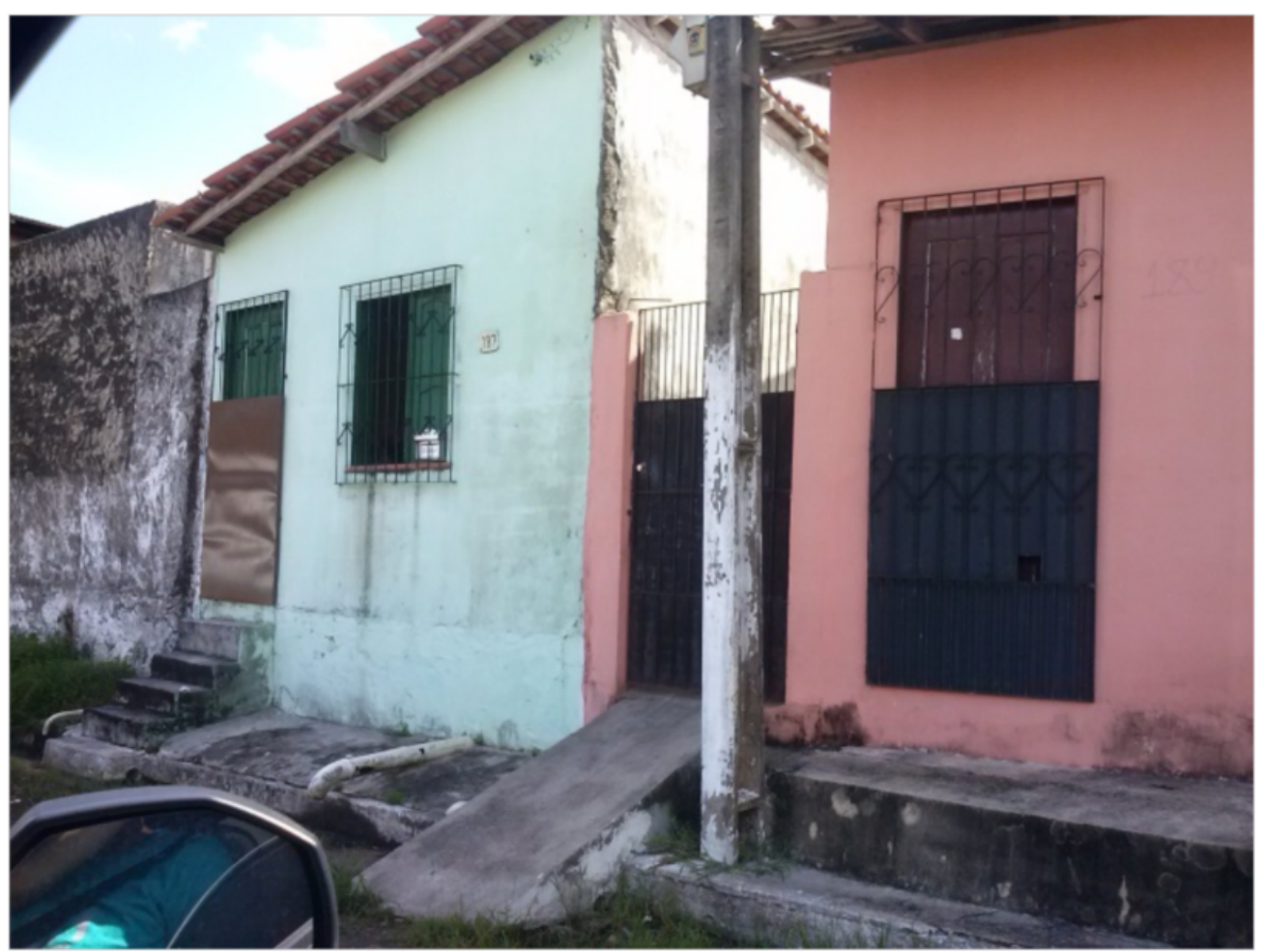

Figura 7. Espaços coletivos inapropriados Fonte: Arquivo pessoal

sive inserindo gestores de saúde e representações da sociedade nesse processo, por meio dos dispositivos já citados, sendo estes porta-vozes das necessidades inerentes aos agravos à saúde.

No mais, é percebido como os aspectos socioespaciais são relevantes quando pensado de modo amplo, associado e regional. As condições impostas determinam aspectos relativos à saúde individual e coletiva, pois se afirmam pela perspectiva social e pelos dispositivos políticos democráticos. Outrossim, como resultado das políticas de desenvolvimento regional e das significações do município, as populações excluídas do processo de urbanização tornam-se alvo direto das falências dos planejamentos, o que envolve toda a rede do SUS e suas políticas de controle de agravos. Todas as implicações quando deficitárias são elementos que definem o cenário da saúde.

\section{Considerações finais}

As condições de organização urbana implicam na ausência ou presença de fatores de risco a saúde que estão em geral condicionados à violência e problemas socioambientais que poderiam ser evitados por meio da inclusão urbanística. No caso da 
saúde, identificou-se a associação a um plano diretor eficiente, que viesse por meio de um planejamento urbano municipal com implicações intersetoriais.

A ausência de um plano que fomente as necessidades reais do município de Castanhal, e a falta de registro da distribuição populacional no território, agride a população por meio dos serviços básicos, como a atenção primária em saúde, particularizando o atendimento, e salientando a supressão da população em frente ao crescimento urbano desorganizado.

O equipamento e o espaço urbano em estudo demostram inferências em suas rotinas e estruturas respectivamente evidenciadas pela ausência de estudos de suas necessidades e problemáticas, assim como pela privação de planejamento urbano direcionado. Somado a isto, não somente esta situação é evidenciada nos achados, pois a pesquisa mostrou evidências de implicações ambientais e sociais, deliberadas por problemas urbanos como o aumento de lixos orgânicos e inorgânicos, e espaços de coletividade urbana inapropriados, que implicam e condições socioespaciais desfavoráveis a saúde coletiva e para o controle de agravos. É necessário, portanto, continuar com pesquisas que identifiquem estes dispositivos e propor novas reflexões quanto estes cenários, a fim de implementar as políticas públicas de saúde.

\section{Referências}

AITH, Fernando Mussa Ambujanra. Direito à saúde e democracia sanitária: experiências brasileiras. Revista de Direito Sanitário, v. 15, n. 3, p. 85-90, 2015. Acesso em 15 de dezembro de 2017Link: http://www.revistas.usp.br/rdisan/article/view/97328/96340. DOI: http://dx.doi.org/10.11606/issn.2316-9044.v15i3p85-90

BARDIN, Laurence. Analise de Conteúdo. Edições 70. Brasil, 2016.

BRASIL. Lei no 10.257/01 (Estatuto da cidade). Regulamento os artigos 182 e 183 a Constituição Federal, estabelece diretrizes gerais da política urbana e da outras providencias. Diário oficial da República Federativa do Brasil, Brasília, DF, 11 jul. 2001. Disponível em: http://www.planalto.gov.br/ccivil_03/Leis/LEIS_2001/L10257.htm

BREVILHERI, Eliane Cristina Lopes; NARCISO, Argéria; PASTOR, Márcia. A lógica territorial na politica de saúde do brasileira. Serv. Soc. Ver. Londrina. v. 16, n. 2, p. 36-61, jan/jun. 2014. Acesso em: 20 de agosto de 2015. Link: https://www.researchgate.net/publication/280766650_A_lo gica_territorial_na_politica_de_saude_brasileira.

CARNEIRO, Jr, Nivaldo; SILVEIRA, Cássio. Organização das práticas de atenção primária em saúde no contexto dos processos de exclusão/inclusão social. Cadernos de 
Saúde Pública, Rio de Janeiro. v.19, n. 6, p.1827-1835, nov/dez. 2003. Acesso em 20 janeiro de 2017. Link: http://www.scielo.br /scielo.php?pid=S0102-311X2003000600026 \&script=sci_abstract\&tlng=pt

CRESWELL, John. Research Design: Qualitative, Quantitative, and Mixed Methods Approaches. 4 Ed. Sage Publications, 2013.

DA TRINDADE JR, Saint Clair. Grandes projetos, urbanização do território e metropolização na Amazônia. Terra Livre, v. 1, n. 26, p. 177-194, 2015. Acesso em 20 agosto de 2015. Link: https://www.agb.org.br/publicacoes/index.php/ terralivre/article/view/214/198

DIAS, Maria Fonseca Tereza; FIGUEIREDO, Lorena Mello. Questões de política e questões de princípio: o direito à moradia e à participação popular na política de urbanização do aglomerado da serra, em belo horizonte. Nomos: Revista do Programa de Pós-Graduação em Direito da Universidade Federal do Ceará, v. 35, n. 2, p 274-293, 2016. Acesso em: 20 de agosto de 2015. Link: http://www.periodicos.ufc.br/nomos/article/view/1285

DOS SANTOS, Edileri Machado; KIRSCHBAUM, Débora Isane Ratner. A trajetória histórica da visita domiciliária no Brasil: uma revisão bibliográfica. Revista eletrônica de Enfermagem. v. 10, n. 1, p. 220-227. 2009. Acesso em: 30 de agosto de 2015. Link: https://revistas.ufg.br/fen/article/view/8014/5797

DOS SANTOS, Jessyca; DIAS, Mauricio L; COSTA, Cristiane. FERREIRA, Mônica S. SILVA, Nelma. Terra Firme: Uma Reflexão Sobre O Atual Processo De Regularização Fundiária. Revista Universo \& Extensão, v. 3, n. 3, 2015. Acesso em 10 de setembro de 2015. Link: http://www.revistaeletronica.ufpa.br/index.php/univer so_extensao/article/viewArticle/353

FARIA, Rivaldo Mauro; BORTOLOZZI, Arleude. Espaço, território e saúde: Contribuições de Milton Santos para o tema da Geografia da Saúde no Brasil. Revista RA'E GA. Curitiba, n. 17, ed. UFPR. p. 31-41, 2009. Acesso em: 12 de setembro de 2015.Link: http://webcache.googleusercontent.com/search?q=cache :B9SglEADMtlJ:www.rets.epsjv.fiocruz.br/sites/defaul t/files/espaco_territoiro_e_saude.pdf $+\& \mathrm{~cd}=1 \& \mathrm{hl}=\mathrm{pt}-\mathrm{BR} \& \mathrm{ct}=\mathrm{clnk} \& \mathrm{gl}=\mathrm{br}$

FERRAZ, Raul Dias.; BATISTA, Claúdia Karina Ladeia. A influência do local de moradia no processo de exclusão social: uma análise da situação dos moradores de rua. ANAIS DO SCIENCULT, v. 7, n. 1, p. 388-401, 2017. Acesso em: 12 de setembro de 2015. Link: http://anaisonline.uems.br/index.php/sciencult/article/view/4661/0

GLATT, Kevin, OKUNSERI, Christopher., FLANAGAN, Diane, SIMPSON, Pippa., CAO, Yumei, WILLIS, Earnestine. Evaluation of an oral health education session for Early Head Start home visitors. Journal of public health dentistry, v. 76, n. 3, p. 167-170, 2016. Acesso em 13 março de 2017. Link: https://www.ncbi.nlm.nih.gov/pubmed/27589666 . DOI: https://doi.org/10.1111/jphd.12140

GOMES, Bruno Silva de Moraes; BASTOS, Suzana Quinit de Andrade; FERES, Flávia Lúcia Chen. Espaços urbanos saudáveis e os determinantes sociais da saúde (dss). Anais, p. 1-20, 2016. Acesso em 20 de janeiro de 2017. Link: http://www.abep.org.br/publicacoes/ index.php/anais/article/viewFile/2161/2116 
HOLANDA, Anna Carolina. G; NEGRÃO, Márcia Regina Gama. Reflexões sobre a questão habitacional no estado do Pará. Anais: In: XIII Encontro da associação nacional de pós-graduação e pesquisa em planejamento urbano e regional, 2009. Anais do. Encontros Nacionais da ANPUR. Florianópolis. Santa Catarina. Brasil., v. 13, 2009. Disponível em:

JACK, S; DICENSO, A; LOHFELD, L. Opening doors: Factors influencing the establishment of a working relationship between paraprofessional home visitors and at-risk families. Canadian Journal of Nursing Research Archive, v. 34, n. 4, 2016. Acesso em: 30 de novembro de 2017. Link: https://www.ncbi.nlm.nih.gov/pubmed/12619478

LIMA, Francisco Willams Campos. Controle social e descentralização na gestão da política educacional de Castanhal-PA. 2014. Tese (Doutorado). Doutorado em Educação, Universidade federal do Pará, Instituto de Ciências da Educação, Belém, 2014.

MACHADO, Jefferson Rogério Marques; UCKER, Fernando Ernesto; JUNIOR, Milton Gonçalves da Silva; ALONS, Ressiliane Ribeiro Prata. Situação do saneamento básico no bairro vila mutirão na cidade de goiânia-go. RENEFARA, v. 8, n. 2, p. 136-145, 2016. Acesso em: 20 de junho de 2017. Link: https://www.fara.edu.br/sipe/index.php/ renefara/article/view/380/pdf_34

MALTA, Deborah Carvalho., MORAIS NETO, Otaliba Libano., SILVA, Marta Maria AIves da, ROCHA, Dais, CASTRO, Adriana Miranda de, REIS, Ademar Arthur Chioro dos, AKERMAN, Marco. Política Nacional de Promoção da Saúde (PNPS): capítulos de uma caminhada ainda em construção. Ciênc saúde coletiva, v. 21, n. 6, p. 1683-94, 2016. Acesso em 15 de agosto de 2017. Link: http://www.scielo.br/scielo.php?script=sci _arttext\&pid=S1413-81232016000601683 \&lng=en\&nrm=iso\&tlng=pt

MARICATO, Ermínia. Planejamento para a crise urbana no Brasil. In: Maricato, Ermínia. Brasil, Cidades: Alternativas para a crise urbana. 5 ed. Petropólis: Vozes, 2011.

MERCÊS, Simaia. Rede de avaliação e capacitação para a implementação dos planos diretores participativos. Pará: Relatório Estadual. Anexo em DVD In: SANTOS JÚNIOR, Orlando Alves dos; Montadon, Daniel Todmann. (org.) Os planos diretores municipais pós Estatuto da cidade: balanço crítico e perspectivas. Rio de Janeiro: Letra Capital: Observatório das Metrópoles, 2011. Editora Fiocruz.

OLIVEIRA, Janine Patrícia Melo; OLIVEIRA, Jaline Melo; BARRETO, Eloana de Souza; SILVA, Saulo Soares da; SILVA, Sabrina Soares; MARACAJÁ, Patrício Borges. Saúde/doença: as consequências da falta de saneamento básico. Informativo Técnico do Semiárido, v. 9, n. 2, p. 23-29, 2015. Acesso em 14 de dezembro de 2015. Link: http://www.gvaa.com.br/revista/index.php/INTESA/article/view/3592/3239 .

OLIVEIRA, Rosane Cristina; LIMA, Jaqueline de Cássia Pinheiro. Plano Diretor Municipal e a questão da participação popular na construção do projeto de remodelação urbana na Baixada Fluminense. Revista Espaço Acadêmico, v. 15, n. 176, p. 15-26, 2015. Acesso em: 20 de janeiro de 2016. Link: http://periodicos.uem.br/ojs/index.php /EspacoAcademico/article/view/28811.

PAIM, Jairnilson S.; ALMEIDA FILHO, Naomar. Saúde coletiva: uma"nova saúde pública"ou campo aberto a novos paradigmas. Revista de saúde pública, v. 32, n. 4, p. 299-316, 1998. Acesso em: 20 de janeiro de 2016. Link: http://www.scielo.br/scielo.php? 
pid=S0034-89101998000400001\&script=sci_abstract\&tlng=pt.

DOI: http://dx.doi.org/10.1590/S0034-89101998000400001.

PEREIRA, Rafaela Rodrigues. Território, Saúde e ambiente: Novas formas de articulação. Revista de Geografia. V.18. n.1. p. 193-206, jan/jun. 2009. Acesso em: 15 de outubro de 2015. Link: http://www.uel.br/revistas/uel/index.php/ geografia/article/view/2512/2263 . DOl: http://dx.doi.org/10.5433/2447-1747.2009v18n1p193

PINTO, Antônio Germane Alves; JORGE, Maria Salete Bessa. Prática clínica na estratégia saúde da família: relações entre equipe e usuários no território urbano. Gestão e Saúde, v. 6, n. 2, p.1514-1529, 2015. Acesso em 24 de agosto de 2016. Link: http://periodicos.unb.br/index.php/rgs/article/view/22483/16080 . DOI: http://dx.doi.org/10.18673/gs.v6i2.22483

SANTOS, Lenir. Região de saúde e suas redes de atenção: modelo organizativosistêmico do SUS. Ciência \& Saúde Coletiva, v. 22, p. 1281-1289, 2017. Acesso em 20 de janeiro de 2017. Link: http://www.scielo.br/scielo.php?pid=S1413 81232017002401281\&script=sci_abstract\&tlng=pt . DOI: http://dx.doi.org/10.1590/141381232017224.26392016

SILVA, E. C. Rede urbana e a cidade de Castanhal/Pa. Boletim Amazônico de Geografia, v. 1 , n. 2 , p. $43-53,2015$.

SIMONIAN, Ligia Terezinha Lopes. Uma relação que se amplia: Fotografia e ciência sobre a Amazônia Papers do NAEA.. Belém. n. 196, 2006.

SIPRIANO, Claudio Alex de Souza; MOREIRA, Janine. M; SORATTO, Jacks. Participação popular e controle social: e o empowerment dos conselheiros locais de saúdecls. Criar Educação, v. 4, n. 1, 2015. Acesso: 20 de janeiro de 2017. Link: http://periodicos.unesc.net/criaredu/article/view/1244/1815 .

SOUSA, Izautina Vasconcelos, BRASIL, Christina César Praça, DA SILVA, Raimunda Magalhães, VASCONCELOS, Dayse Paixão e, SILVA, Kellyane Abreu, BEZERRA, Illana Nogueira, FINAN, Timoty J.. Diagnóstico participativo para identificação de problemas de saúde em comunidade em situação de vulnerabilidade social. Ciência \& Saúde Coletiva, v. 22, n. 12, p. 3945-3954, 2017. Acesso em 15 de junho de 2017. Link: http://www.scielo.br/scielo.php?script= sci_abstract\&pid=S14138 1232017021203945\&lng=pt\&nrm=iso .DOI: http://dx.doi.org/10.1590/1413812320172212.25012017

SOUZA, Cezarina Maria Nobre. Participação dos cidadãos na gestão do saneamento básico no Pará. Novos Cadernos NAEA, v. 18, n. 2, p. 261-274. 2015. Acesso em 20 de agosto de 2017. Link: https://periodicos.ufpa.br/index.php/ncn/article/view/1934/2721.

SOUZA, Marcelo Lopes. Mudar a cidade. Uma introdução crítica ao planejamento e à gestão urbanos. Rio de Janeiro: Bertrand Brasil. 6ª Ed, 2010.

YIN, Robert. Estudo de caso: planejamento e métodos. Bookman. 2016

VILLAÇA, Flávio. Uma contribuição ao planejamento urbano no Brasil. In: DEAK, C.; Schiffer, S. O processo de urbanização no Brasil. São Paulo: EDUSP; FUPAM, 1999. 